\title{
Lipoprotein Lipase Deficiency: Diet is the Key!
}

\author{
Kshitija Patil ${ }^{1}$ - Neerja Gupta ${ }^{1}$ (D) \\ Received: 21 December 2020 / Accepted: 21 December 2020 / Published online: 12 January 2021 \\ (C) Dr. K C Chaudhuri Foundation 2021
}

Lipoprotein lipase (LPL) deficiency (OMIM \#238600) is a rare autosomal recessive familial chylomicronemia with a prevalence of 1 in 1,000,000 [1]. It occurs due to a defect in $L P L$ which is located on chromosome 8p21.3. It causes absent or truncated LPL enzyme with a defective catalytic activity resulting in impaired clearance of chylomicrons from the plasma causing severe hypertriglyceridemia. LPL deficiency usually presents with abdominal pain, hepatosplenomegaly, acute pancreatitis, and eruptive cutaneous xanthomata in childhood. The disease may present directly in adulthood. Recurrent pancreatitis is one of the most debilitating complications of LPL deficiency.

Kuthiroly et al. describe the biochemical and molecular profile of a cohort of 15 pediatric patients that were followed for more than a decade [2]. Most of the patients in this cohort were diagnosed incidentally due to a lipemic serum at a mean age of 7 months. A detailed indigenous fat-restricted diet plan as a first-line treatment plan reversed lipemia retinalis in 14 patients and prevented the occurrence of pancreatitis. More than 220 pathological variants in $L P L$ have been identified with two-thirds being missense in nature [1]. Majority of the variants are located on exons 2, 5, and 6 of $L P L$ [1]. Kuthiroly et al. identified a common splice site variant in intron 1 and a missense variant in exon 5 in the Indian cohort [2].

The mainstay of long-term management is the restriction of dietary fat to $\leq 20 \mathrm{~g} / \mathrm{d}[1,3]$ with plasma triglycerides monitoring. Dietary recommendations, as clarified by Kuthiroly et al. are important as the type of foods available varies in different regions [2]. A predominantly vegetarian diet offers better triglyceride control. For good compliance and better outcomes, it is important that the diet is indigenous, comprises foods that are easily available and affordable, and the family incorporates the modified diet as a family diet. Exercise induces increased LPL enzyme activity in skeletal muscles and is useful only in case of

Neerja Gupta

neerja17@gmail.com

1 Division of Genetics, Department of Pediatrics, All India Institute of Medical Sciences, New Delhi 110029, India residual LPL activity [4]. Lipid-lowering agents have no role in reducing chylomicrons in LPL deficiency [3].

An adeno-associated viral vector (AAV)1-LPL gene therapy, alipogene tiparvovec, that introduced functional copies of the $L P L$ into the muscle tissue of patients was initiated in a few countries but later on withdrawn due to uncertainties about reimbursement and poor demand [5]. Other newer treatment modalities include a second-generation antisense oligonucleotide inhibitor of apolipoprotein C-III (APOC3), volanesorsen which leads to a reduction in hepatic production of APOC3, thereby decreasing hypertriglyceridemia [6]. Pradigastat, an orally administered diacylglycerol $\mathrm{O}$-acyltransferase 1 (DGAT1) inhibitor that catalyzes the final step in triglyceride synthesis is another treatment modality [7]. Evinacumab, a monoclonal antibody to angiopoietin-like protein 3 (ANGPTL3), which is an inhibitor of LPL and endothelial lipase has also been found to be effective [8].

A recent study on the quality of life of LPL deficiency patients has highlighted the unmet need for appropriate and consistent dietary advice, as well as education and sources of information on LPL deficiency for patients and family members [9].

The study by Kuthiroly et al. seems encouraging in the overall management of childhood LPL deficiency [2]. However, more studies from other parts of India are needed to assess the burden and study the phenotypic and genotypic spectrum of LPL deficiency.

\section{Compliance with Ethical Standards}

Conflict of Interest None.

\section{References}

1. Balasubramanian S, Aggarwal P, Sharma S. Lipoprotein Lipase Deficiency. [Updated $2020 \mathrm{Jul}$ 8]. In: stat pearls [internet]. Treasure Island: StatPearls Publishing; 2020.

2. Kuthiroly S, Yesodharan D, Radhakrishnan N, et al. Lipoprotein lipase deficiency. Indian J Pediatr. 2020. https://doi.org/10.1007/ s12098-020-03305-z. 
3. Brahm AJ, Hegele RA. Chylomicronaemia-current diagnosis and future therapies. Nat Rev Endocrinol. 2015;11(6):352-62.

4. Seip RL, Angelopoulos TJ, Semenkovich CF. Exercise induces human lipoprotein lipase gene expression in skeletal muscle but not adipose tissue. Am J Phys. 1995;268(2 Pt 1):E229-36.

5. Gaudet D, Méthot J, Kastelein J. Gene therapy for lipoprotein lipase deficiency. Curr Opin Lipidol. 2012;23(4):310-20.

6. Witztum JL, Gaudet D, Freedman SD, et al. Volanesorsen and triglyceride levels in familial chylomicronemia syndrome. N Engl J Med. 2019;381(6):531-42.

7. Meyers CD, Tremblay K, Amer A, Chen J, Jiang L, Gaudet D. Effect of the DGAT1 inhibitor pradigastat on triglyceride and apoB48 levels in patients with familial chylomicronemia syndrome. Lipids Health Dis. 2015;14:8.
8. Gaudet D, Gipe DA, Pordy R, Sasiela W, Chan KC, Khoury E. Safety and efficacy of evinacumab, a monoclonal antibody to ANGPTL3, in patients with homozygous familial hypercholesterolemia receiving concomitant lipid-lowering therapies. J Clin Lipidol. 2016;10(3):715.

9. Neelamekam S, Kwok S, Malone R, Wierzbicki AS, Soran H. The impact of lipoprotein lipase deficiency on health-related quality of life: a detailed, structured, qualitative study. Orphanet J Rare Dis. 2017;12(1):156.

Publisher's Note Springer Nature remains neutral with regard to jurisdictional claims in published maps and institutional affiliations. 